Research paper

\title{
New operational mode of an electrochemical reactor and its application to the degradation of levofloxacin
}

\author{
Robson S. Rocha ${ }^{\mathrm{a}, *}$, Ricardo B. Valim ${ }^{\mathrm{b}}$, Leandro C. Trevelin ${ }^{\mathrm{b}}$, Fernando L. Silva ${ }^{\mathrm{b}}$, \\ Juliana R. Steter ${ }^{\mathrm{b}}$, Marcelo Zaiat ${ }^{\mathrm{c}}$, Marcos R.V. Lanza ${ }^{\mathrm{b}, \mathrm{d}, *}$ \\ a Escola de Engenharia de Lorena, Universidade de São Paulo, Estrada Municipal do Campinho sn, 12602-810, Lorena, Sao Paulo, Brazil \\ b Instituto de Química de São Carlos, Universidade de São Paulo, Av. Trabalhador São-carlense 400, 13560-970, São Carlos, Sao Paulo, Brazil \\ ${ }^{c}$ Escola de Engenharia de São Carlos, Universidade de São Paulo, Av. Trabalhador São-carlense 400, 13560-970, São Carlos, Sao Paulo, Brazil \\ d Instituto Nacional de Tecnologias Alternativas para Deteç̧ão, Avaliação Toxicológica e Remoção de Micropoluentes e Radioativos (INCT-DATREM), Instituto de \\ Química, Unesp, Caixa Postal 355, 14800-900 Araraquara (SP)
}

\section{A R T I C L E I N F O}

\section{Keywords:}

Single-pass flow electrochemical reactor

Levofloxacin degradation

Gas diffusion electrode

Fenton reaction

\begin{abstract}
A B S T R A C T
The flow-by electrochemical reactor is generally used in batch mode with extended process time in order to achieve high efficiency in the removal of organic contaminant from aqueous solution. Moreover, the batch mode system is inappropriate for the treatment of wastewater in high volume or as a continuous stream. This paper presents a new operational mode for the electrochemical reactor in which the electrolyte passes over the electrodes just once at a reduced flow rate and with high hydraulic retention time. The concentration of hydrogen peroxide generated in the reactor running in the single-pass flow mode attained $10.2 \mathrm{mg} \mathrm{L}^{-1} \mathrm{~cm}^{-2}$ in acid medium, a value similar to that obtained previously with the same type of reactor operating in batch mode. In the single-pass mode, the electrochemical reactor showed high rates of removal of the antibiotic levofloxacin (initial $50 \mathrm{mg} \mathrm{L}^{-1}$ ) and organic load (initial $130 \mathrm{mg} \mathrm{L}^{-1}$ ) up to 99 and $86 \%$, respectively, when operated under electro- or photo-Fenton degradation conditions (acid medium with $\mathrm{Fe}^{2+}$ ions; absence or presence of UV irradiation). Degradation of levofloxacin generated high levels of nitrate (up to $4.5 \mathrm{mg} \mathrm{L}^{-1}$ ) and various byproducts that could be identified by liquid chromatography-mass spectrometry.
\end{abstract}

\section{Introduction}

Contamination of the environment by biologically active compounds has increased significantly over recent decades with numerous types of such agents, along with their metabolites, having been detected in surface waters [1-3]. This issue is of particular concern given the multiple potential vectors that allow active compounds to enter surface water systems, such as inappropriate disposal of expired or unused medication along with limitations and failures of sewage treatment processes $[1,3,4]$.

Antibiotics feature high in the list of biologically active compounds most commonly employed in human medicine and in veterinary practice. Among this class of therapeutic agents, the fluoroquinolone-based drugs are consumed in the largest quantities by far because of their effectiveness and broad-spectrum activity. However, such widespread use, particularly in non-therapeutic applications in animal agriculture, has contributed to the emergence of a high level of resistance [2].

According to Wei et al. [4], up to $80 \%$ of ingested fluoroquinolone can be excreted in an unchanged form that can enter the wastewater system. Since current public sewage treatment techniques are ineffective in removing this type of compound, the risk of contamination of surface waters and, ultimately, of the public water supply, is substantial $[2,4,5]$. On this basis, the present paper aims to present an alternative to the electrochemical treatment of water contaminated with the widely used fluoroquinolone antibiotic levofloxacin [1].

Electrochemical technology can be employed in the treatment of wastewater contaminated with a variety of organic compounds, either by direct degradation or through the generation of oxidizing species such as chlorine, hydrogen peroxide $\left(\mathrm{H}_{2} \mathrm{O}_{2}\right)$ and ozone [6-10]. However, a number of studies have shown that, among the different techniques available for the removal of organic compounds [11-25], those employing $\mathrm{H}_{2} \mathrm{O}_{2}$ are especially effective through generation of highly oxidizing and non-selective hydroxyl radicals [8].

While the peroxide can be produced in various ways $[8,9,12,13,26-33]$, its formation generally depends on the concentration of oxygen in the aqueous medium, a that factor imposes serious limitations on $\mathrm{H}_{2} \mathrm{O}_{2}$ generation. According to Reis et al. [34], this limitation can be avoided through the use of a porous/hydrophobic gas

\footnotetext{
* Corresponding authors.

E-mail addresses: robsonsr@uol.com.br (R.S. Rocha), marcoslanza@iqsc.usp.br (M.R.V. Lanza).
} 
diffusion electrode (GDE) that can provide an unlimited supply of oxygen at the electrode/electrolyte interface. Moreover, using this type of electrode it is possible to regulate the amount of $\mathrm{H}_{2} \mathrm{O}_{2}$ generated for the proposed degradation process by modifying the experimental conditions, particularly the potential/current applied and the flow rate. Not only is the GDE versatile and easy to install, but the same electrode can generate $\mathrm{H}_{2} \mathrm{O}_{2}$ in cells and electrochemical reactors using different aqueous electrolytes under constant current or potential and with flow rates ranging from a few milliliters to hundreds of liters per hour [35-45].

Numerous studies have confirmed the efficient generation of $\mathrm{H}_{2} \mathrm{O}_{2}$ by GDEs in cells and reactors, but the processes employed were typically operated in batch mode whereby a single volume of electrolyte is recirculated for a specified time (which can vary from minutes to several hours) in order to achieve the required efficacy. Batch mode is most effective when the volume of electrolyte is fixed and/or small in comparison with the electrode area, and high levels of organic compound removal can be achieved using this method. On the other hand, batch operation presents severe limitations when high or continuous volumes of electrolyte must to be treated and, in certain cases, it is not possible to complete the process using this mode [35-46].

In light of the above, we propose the use of a flow-by electrochemical reactor operated in the single-pass flow mode in which the electrolyte passes only once inside the reactor. The aim of the present study was, therefore, to determine the efficiency of electrodegradation of levofloxacin in aqueous media performed in the single-pass mode as a function of residence time in the reactor and other control parameters. To this end, we evaluated the amount of antibiotic and total organic carbon (TOC) remaining in the electrolyte after a single passage through the reactor and we identified the byproducts formed during the degradation process.

\section{Experimental}

The study was carried out in two separate stages. Initially, the amount of $\mathrm{H}_{2} \mathrm{O}_{2}$ generated in a GDE operated in the single-pass flow mode was determined, following which the degradation of levofloxacin was investigated under the same experimental conditions. The electrochemical reactor employed in the study comprised two parallel polypropylene plates, held apart by a $2 \mathrm{~mm}$ thick inert rubber spacer, in which one plate was fitted with a commercial Dimensionally Stable Anode type $\mathrm{Cl}_{2}$ (DSA-Cl${ }_{2}^{\circ}$; exposed area $19.4 \mathrm{~cm}^{2}$; De Nora do Brasil) and the other with a GDE cathode (exposed area $19.4 \mathrm{~cm}^{2}$ ), as described previously [34]. The GDE was prepared by the hot pressing procedure using Printex 6L carbon black (Evonik do Brasil Ltda) and was pressurized ( 0.2 bar) with oxygen (for experiments with $\mathrm{H}_{2} \mathrm{O}_{2}$ generation) or nitrogen (for experiments without $\mathrm{H}_{2} \mathrm{O}_{2}$ generation). A Tectrol 30 $\mathrm{Vcc} / 20 \mathrm{~A}$ stabilized voltage source was used to apply a current in the range $25-150 \mathrm{~mA} \mathrm{~cm}^{-2}$ for $\mathrm{H}_{2} \mathrm{O}_{2}$ generation and of $150 \mathrm{~mA} \mathrm{~cm}^{-2}$ in the degradation experiments and the electrochemical reactor was operating in the single-pass flow mode in which the electrolyte was passed through the reactor only once and was sampled immediately after exiting the system.

The electrolytes employed in the $\mathrm{H}_{2} \mathrm{O}_{2}$ generation and levofloxacin degradation (53.2 $\mathrm{mg} \mathrm{L}^{-1}$ of levofloxacin in all the experiments) were: (i) an acidic electrolyte containing $0.05 \mathrm{~mol} \mathrm{~L}^{-1} \mathrm{~K}_{2} \mathrm{SO}_{4}$ (pH adjusted to 2 with $\mathrm{H}_{2} \mathrm{SO}_{4}$ ) with or without $0.1 \mathrm{mmol} \mathrm{L}^{-1} \mathrm{FeSO}_{4}$, and (ii) an alkaline electrolyte containing $0.05 \mathrm{~mol} \mathrm{~L}^{-1} \mathrm{~K}_{2} \mathrm{SO}_{4}$ and $0.1 \mathrm{~mol} \mathrm{~L}^{-1} \mathrm{KOH}(\mathrm{pH}$ 13). Levofloxacin was added to both electrolytes at a final concentration of $50 \mathrm{mg} \mathrm{L}^{-1}$. The electrolyte was impelled by a peristaltic pump connected to the inlet of the electrochemical reactor and exited through a tube with a UV lamp (radiating at $254 \mathrm{~nm}$ ) attached to the reactor outlet. Experiments were performed with electrolyte flow rates of 300, 600 or $1200 \mathrm{~mL} \mathrm{~h}^{-1}$ under conditions of constant temperature $\left(23^{\circ} \mathrm{C}\right)$ and in the absence or presence of UV irradiation. The electrolyte was monitored after an interval of $15 \mathrm{~min}$ by collecting a $30 \mathrm{~mL}$ sample of the effluent stream at the system output.

Concentrations of $\mathrm{H}_{2} \mathrm{O}_{2}$ were determined using the standard spectrophotometric method (ammonium molybdate in acidic medium at $350 \mathrm{~nm}$ ) [12] and values are presented as a function of the exposed area of the GDE.

In the degradation experiments, samples of electrolyte were analyzed by high performance liquid chromatography (HPLC) using a Shimadzu Prominence LC 20 AT instrument fitted with a Phenomenex Luna C-18 column $(250 \times 4.6 \mathrm{~mm}$ id; $5 \mathrm{um})$. The mobile phase consisted of $0.5 \%$ formic acid in water (solvent $\mathrm{A}$ ) and acetonitrile (solvent B) supplied at a flow rate of $1 \mathrm{~mL} \mathrm{~min}^{-1}$. The elution program was: 0-0.5 min, $15 \%$ B (isocratic); $0.50-0.51 \mathrm{~min}, 15-30 \%$ B (step); 0.51-7.50 min, $30-75 \%$ B (linear gradient); and 7.5-12.00 min, $75-15 \%$ (linear gradient). Detection was at $270 \mathrm{~nm}$ and a quantification curve was used for the range of $1-80 \mathrm{mg} \mathrm{L}^{-1}$ of levofloxacin. Products of the degradation reactions were identified by HPLC coupled with mass spectrometry (MS) using a Thermo Scientific Accela 1250 pump and LTQ-Orbitrap mass analyzer in combination with a photodiode array detector and a Waters Micromass ESCi multi-mode ionization source. Anions produced during electrolysis were analyzed by ion chromatography performed at $30^{\circ} \mathrm{C}$ using a Metrohm model 850 instrument equipped with a Phenomenex Star-Ion A300 column $(100 \times 4.6 \mathrm{~mm}$ i.d.) and coupled to a conductivity detector. Elution was with a mobile phase containing $1.7 \mathrm{mmol} \mathrm{L}^{-1} \mathrm{NaHCO}_{3}$ and $1.8 \mathrm{mmol} \mathrm{L}^{-1} \mathrm{Na}_{2} \mathrm{CO}_{3}$ supplied at a flow rate of $1.5 \mathrm{~mL} \mathrm{~min}^{-1}$, while the suppression solution comprised $0.1 \mathrm{~mol} \mathrm{~L}^{-1} \mathrm{H}_{2} \mathrm{SO}_{4}$ in ultrapure water using quantification curve for the range of 1-to $100 \mathrm{mg} \mathrm{L}^{-1}$ of nitrate and nitrite. A Shimadzu TOC-VCPH analyzer was used to monitor the removal of TOC during electrolysis and the initial organic loading is $130 \mathrm{mg} \mathrm{L}^{-1}$, approximately, in all experiments using quantification curve for the range of $1-500 \mathrm{mg} \mathrm{L}^{-1}$ of organic carbon.

\section{Results and discussion}

Although the literature is replete with studies concerning the generation of $\mathrm{H}_{2} \mathrm{O}_{2}$ and the degradation of organic pollutants, the experiments were generally performed in batch mode in which a single volume of electrolyte was recirculated over the electrodes throughout the experimental period in order to achieve the efficiencies reported [26-28,30,39-42,44]. However, application of a batch mode system in the treatment of a high volume or a continuous stream of wastewater is extremely limited.

The reactor used in this study has been employed previously by Reis et al. [34] for generating $\mathrm{H}_{2} \mathrm{O}_{2}$ and by Barros et al. [47] for the degradation of organic pollutants. In both of these studies, the reactor was operated in the batch mode and excellent efficiencies were achieved. The electrode configuration employed in the reactor was unusual in that it comprised two parallel polypropylene plates, one of which incorporated the DSA- $\mathrm{Cl}_{2}{ }^{\oplus}$ while the other contained the GDE, separated by a $2 \mathrm{~mm}$ thick spacer. The purpose of using this arrangement was to combine the reactions on the surfaces of the anode and the GDE in order to achieve the largest removal of organic contaminant during the single pass of electrolyte over the electrodes.

Since the electrolyte passed only once inside the reactor, each change in $\mathrm{H}_{2} \mathrm{O}_{2}$ generation or degradation parameter was considered to be an independent experiment. Initially, it was necessary to determine the time interval after which the electrolyte should be monitored following a change in an experimental parameter. The results shown in Fig. 1 were obtained from three experiments in which $\mathrm{H}_{2} \mathrm{O}_{2}$ was generated in the electrochemical reactor using an applied current of $150 \mathrm{~mA} \mathrm{~cm}^{-2}$ and flow rates of 300,600 and $1200 \mathrm{~mL} \mathrm{~h}^{-1}$. In these experiments, the electrochemical system was operated continuously and the concentration of $\mathrm{H}_{2} \mathrm{O}_{2}$ in the effluent stream was determined over a $120 \mathrm{~min}$ period. At the end of each experiment, electrolyte was pumped while the reactor was in the non-polarized state in order to wash the complete electrochemical system. In all cases, a steady state 


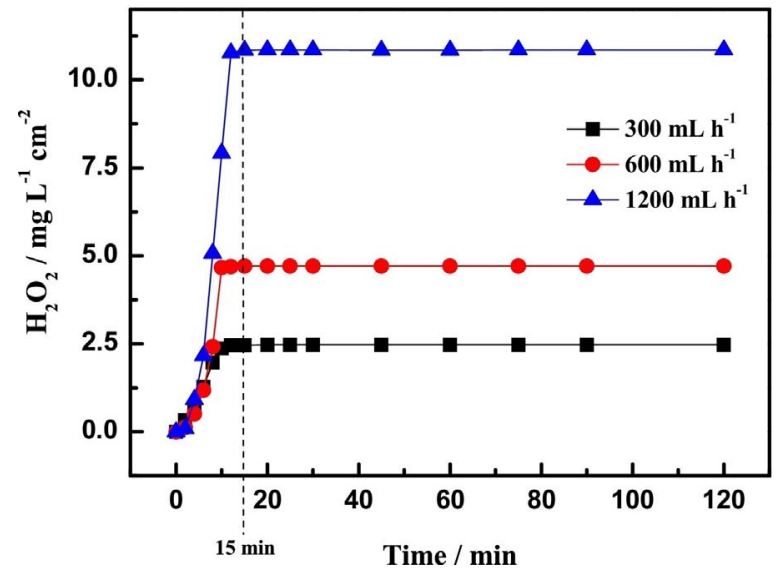

Fig. 1. Variations in the concentration of $\mathrm{H}_{2} \mathrm{O}_{2}$ generated as a function of time in three experiments performed with flow rates of $300(-), 600$ (-) and $1200(-) \mathrm{mL} \mathrm{h}^{-1}$. The electrolyte was $0.05 \mathrm{~mol} \mathrm{~L}^{-1} \mathrm{~K}_{2} \mathrm{SO}_{4}$ (adjusted to $\mathrm{pH} 2$ ) and the total process time per experiment was $120 \mathrm{~min}$.

was attained within $12 \mathrm{~min}$ from the start of the experiment and no significant variations were observed in $\mathrm{H}_{2} \mathrm{O}_{2}$ concentrations after this time with any of the flow rates studied. Therefore, samples were collected after an interval of $15 \mathrm{~min}$ in all further experiments.

Fig. 2 shows the steady state concentrations of $\mathrm{H}_{2} \mathrm{O}_{2}$ generated in the electrochemical system as functions of applied current density, flow rate and electrolyte employed. In both acidic and alkaline media, and at all of the flow rates studied, increases in applied current gave rise to
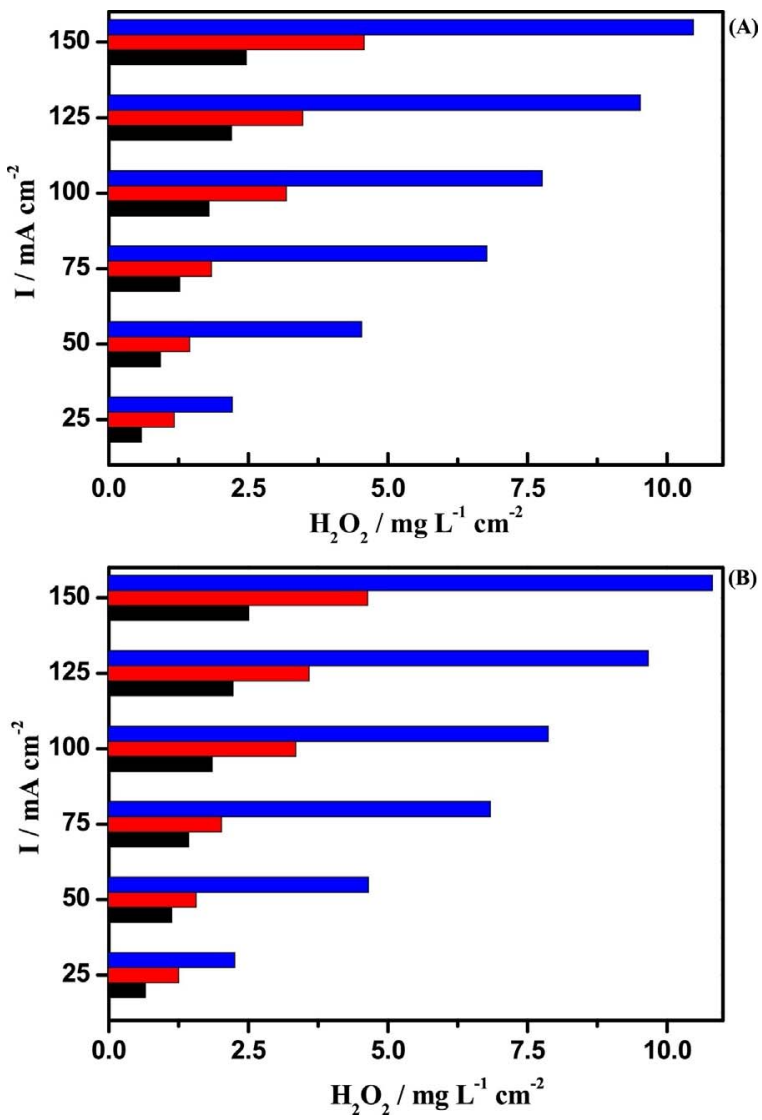

Fig. 2. Effects of applied current density on the concentration of $\mathrm{H}_{2} \mathrm{O}_{2}$ generated with flow rates of $300(-), 600(-)$ and $1200(-) \mathrm{mL} \mathrm{h}^{-1}$ in: (a) acidic electrolyte containing $0.05 \mathrm{~mol} \mathrm{~L}^{-1} \mathrm{~K}_{2} \mathrm{SO}_{4}$ (adjusted to $\mathrm{pH}$ 2) plus $0.05 \mathrm{~mol} \mathrm{~L}^{-1} \mathrm{FeSO}_{4}$, and (b) alkaline electrolyte containing $0.05 \mathrm{~mol} \mathrm{~L}^{-1} \mathrm{~K}_{2} \mathrm{SO}_{4}$ and $0.1 \mathrm{~mol} \mathrm{~L}^{-1} \mathrm{KOH}(\mathrm{pH} 13)$. The initial solution used in all of the degradation experiments contains $53.2 \mathrm{mg} \mathrm{L}^{-1}$ of levofloxacin. significant increases in $\mathrm{H}_{2} \mathrm{O}_{2}$ generation. This behavior was as expected since, according to Eq. (1) [48] and Eq. (2) [34], the concentration of oxygen on the surface of the GDE was constant, thus increases in the energy supplied should lead to the generation of higher concentrations of $\mathrm{H}_{2} \mathrm{O}_{2}$ irrespective of the flow rate or electrolyte studied.

$\mathrm{O}_{2}+\mathrm{H}_{2} \mathrm{O}+2 \mathrm{e}^{-} \rightarrow \mathrm{HO}_{2}^{-}+\mathrm{OH}^{-}$

$\mathrm{O}_{2}+2 \mathrm{H}^{+}+2 \mathrm{e}^{-} \rightarrow \mathrm{H}_{2} \mathrm{O}_{2}$

As shown in Fig. 2, flow rate is an important factor in determining the concentration of $\mathrm{H}_{2} \mathrm{O}_{2}$ formed, principally because it controls the time during which the electrolyte is in contact with the surface of the electrodes. However, flow rate also exerts a direct influence on the production of $\mathrm{H}_{2} \mathrm{O}_{2}$ at the surface of the GDE. According to Reis et al. [34], increasing the flow rate generates a greater hydrodynamic force at the GDE surface which, in turn, promotes greater penetration of the liquid into the structure of the electrode leading to a reduction in the formation of $\mathrm{H}_{2} \mathrm{O}_{2}$. These authors reported a decrease of approximately $40 \%$ in $\mathrm{H}_{2} \mathrm{O}_{2}$ generation when the flow rate was increased from 50 to $300 \mathrm{~L} \mathrm{~h}^{-1}$, indicating that low flow rates not only provide a longer residence time of the electrolyte but also minimize the hydrodynamic forces on the surface of the GDE. In contrast, the results presented in Fig. 2 show that an increase in flow rate promoted an increase in $\mathrm{H}_{2} \mathrm{O}_{2}$ generation, with maximum production being attained at $1200 \mathrm{~mL} \mathrm{~h}^{-1}$. This behavior differs from that reported previously because of the differences in the magnitude of the flow rates studied, which were below $1.2 \mathrm{~L} \mathrm{~h}^{-1}$ in the present investigation and between 50 and $300 \mathrm{~L} \mathrm{~h}^{-1}$ in the study by Reis et al. [34]. Clearly, reduction of the flow rate from 50 to $1.2 \mathrm{~L} \mathrm{~h}^{-1}$ promoted a significant reduction in the hydrodynamic forces on the surface of the GDE.

The nature of the electrolyte exerted only a small influence on $\mathrm{H}_{2} \mathrm{O}_{2}$ generation, in that the maximum difference observed in $\mathrm{H}_{2} \mathrm{O}_{2}$ concentration in alkaline and acidic media was only $4.6 \pm 0.2 \%$. This finding suggests that the primary consideration in choosing an electrolyte should be the treatment method and not the amount of $\mathrm{H}_{2} \mathrm{O}_{2}$ generated.

In the present study, maximal generation of $\mathrm{H}_{2} \mathrm{O}_{2}$ was attained at a flow rate of $1200 \mathrm{~mL} \mathrm{~h}^{-1}$ to yield $10.8 \mathrm{mg} \mathrm{L}^{-1} \mathrm{~cm}^{-2}$ of peroxide in alkaline electrolyte and $10.30 \pm 0.12 \mathrm{mg} \mathrm{L}^{-1} \mathrm{~cm}^{-2}$ in acidic electrolyte. These concentrations are slightly lower than the $17.5 \mathrm{mg} \mathrm{L}^{-1} \mathrm{~cm}^{-2}$ reported by Rocha et al. [49] and the $18.6 \mathrm{mg} \mathrm{L}^{-1} \mathrm{~cm}^{-2}$ achieved by Reis et al. [34] using the same type of electrochemical reactor in batch mode with acidic medium circulated at a flow rate of $50 \mathrm{~L} \mathrm{~h}^{-1}$. The lower concentration of $\mathrm{H}_{2} \mathrm{O}_{2}$ observed in the present study was associated with the operational mode of the electrochemical reactor since in the batch mode method a single volume of electrolyte was recirculated within the reactor for $120 \mathrm{~min}$ while in the continuous flow method the electrolyte performed just one pass over the surface of the GDE.

Experiments involving the degradation of levofloxacin were performed using the same electrochemical system as in the $\mathrm{H}_{2} \mathrm{O}_{2}$ generation experiments, and the contributions of anodic degradation, UV degradation and $\mathrm{H}_{2} \mathrm{O}_{2}$ degradation, along with the synergism of these techniques in the absence or presence of $\mathrm{Fe}^{2+}$ ions, were evaluated. In order to achieve the best removal of antibiotic and organic load at each of the flow rates studied, and to provide the highest current density for anodic degradation while maintaining maximal $\mathrm{H}_{2} \mathrm{O}_{2}$ generation, all further experiments were carried out with an applied current density of $150 \mathrm{~mA} \mathrm{~cm}^{-2}$.

Five experiments were performed using the acidic electrolyte in the presence of $\mathrm{Fe}^{2+}$ ions as follows: (i) anodic degradation (GDE pressurized with $\mathrm{N}_{2}$ for electrochemical process only; no UV irradiation), (ii) anodic degradation with UV irradiation (GDE pressurized with $\mathrm{N}_{2}$ ), (iii) UV irradiation (non-polarized reactor and GDE pressurized with $\mathrm{N}_{2}$ ), (iv) electro-Fenton degradation (GDE pressurized with $\mathrm{O}_{2}$ for electrochemical/chemical process; no UV irradiation) and (v) photo- 

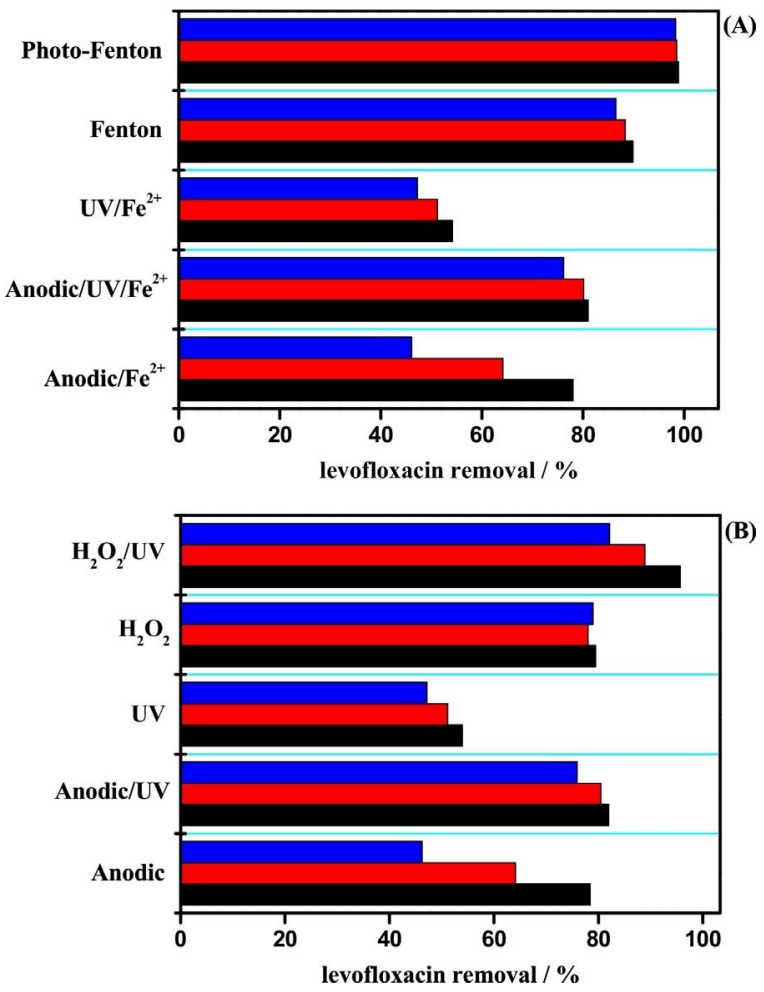

Fig. 3. Percentage removal of levofloxacin in degradation experiments performed at $150 \mathrm{~mA} \mathrm{~cm}^{-2}$ and flow rates of $300(-), 600(-)$ and $1200(-) \mathrm{mL} \mathrm{h}^{-1}$ in: (a) acidic electrolyte containing $0.05 \mathrm{~mol} \mathrm{~L}^{-1} \mathrm{~K}_{2} \mathrm{SO}_{4}$ (adjusted to $\mathrm{pH}$ 2) plus $0.05 \mathrm{~mol} \mathrm{~L}^{-1} \mathrm{FeSO}_{4}$, and (b) alkaline electrolyte containing $0.05 \mathrm{~mol} \mathrm{~L}^{-1} \mathrm{~K}_{2} \mathrm{SO}_{4}$ and $0.1 \mathrm{~mol} \mathrm{~L}^{-1} \mathrm{KOH}(\mathrm{pH}$ 13). The initial solution used in all of the degradation experiments contains $53.2 \mathrm{mg} \mathrm{L}^{-1}$ of levofloxacin.

Fenton degradation with UV irradiation (GDE pressurized with $\mathrm{O}_{2}$ for electrochemical/chemical process). As shown in Fig. 3a, less than $80 \%$ of levofloxacin was removed from the acidic electrolyte in the absence of $\mathrm{H}_{2} \mathrm{O}_{2}$ (GDE pressurized with $\mathrm{N}_{2}$; with and without UV irradiation) independent of the flow rate employed. This low removal of antibiotic is associated with the dependency on mass transport to renew molecules on the anode surface and/or on the incidence of UV irradiation. The limitation imposed by mass transport is intensified by the low flow rate applied when the reactor is operated in the continuous flow mode, since this imposes a laminar flow inside the reactor and in the UV lamp compartment [34]. Under these conditions, increasing the flow rate promotes an increase in the internal velocity and consequently a decrease in internal retention time [50]. In the present study, increasing the flow rate in experiments performed in the absence of $\mathrm{H}_{2} \mathrm{O}_{2}$ promoted a decrease in levofloxacin removal which, for anodic degradation, fell from $78.00 \pm 0.09 \%$ at $300 \mathrm{~mL} \mathrm{~h}^{-1}$ to $63.00 \pm 0.08$ and $45 \%$ at 600 and $1200 \mathrm{~mL} \mathrm{~h}^{-1}$, respectively.

In the experiments conducted in acidic medium under Fenton conditions (Fig. 3a), the degradation of levofloxacin was high both in the absence $(88.00 \pm 0.13 \%$ removal) and presence $(99.00 \pm 0.22 \%$ removal) of UV irradiation, independent of the flow rate employed. Although the applied potential ( $-0.7 \mathrm{~V} \mathrm{vs} \mathrm{Ag} / \mathrm{AgCl}$ ) and, consequently, the generation of $\mathrm{H}_{2} \mathrm{O}_{2}$ were identical in both the electro- and photoFenton processes, the removal of antibiotic was higher in the latter because the formation of hydroxyl radicals could be mediated by two catalytic processes, one involving $\mathrm{Fe}^{2+}$ and the other UV irradiation.

The results obtained using the acidic electrolyte are representative of those reported previously for photocatalytic degradation [3], oxidative degradation [2] and sono-degradation [4,6] in which removals approaching $100 \%$ were achieved in $20 \mathrm{~min}$ [3] and 30 days [2]. However, in the present study, the electrolyte underwent a single passage through the reactor (hydraulic retention time of less than $1 \mathrm{~min}$ ) with sampling at the system outlet.

Five experiments were performed using the alkaline electrolyte in the absence of $\mathrm{Fe}^{2+}$ ions as follows: (i) anodic degradation (GDE pressurized with $\mathrm{N}_{2}$ for electrochemical process only; no UV irradiation), (ii) anodic degradation with UV irradiation (GDE pressurized with $\mathrm{N}_{2}$ ), (iii) UV irradiation (non-polarized reactor and GDE pressurized with $\mathrm{N}_{2}$ ), (iv) $\mathrm{H}_{2} \mathrm{O}_{2}$ degradation (GDE pressurized with $\mathrm{O}_{2}$ for electrochemical/chemical process; no UV irradiation) and (v) $\mathrm{H}_{2} \mathrm{O}_{2}$ degradation with UV irradiation (GDE pressurized with $\mathrm{O}_{2}$ for electrochemical/chemical process). Degradations carried out in alkaline electrolyte exhibited similar behavior to those performed in acidic medium, as shown in Fig. 3b. Less than $80 \%$ of the levofloxacin was removed in experiments without $\mathrm{H}_{2} \mathrm{O}_{2}$ generation since these processes are dependent on mass transfer at the anode surface and/or the incidence of UV irradiation. In contrast, antibiotic removal was much higher for processes involving $\mathrm{H}_{2} \mathrm{O}_{2}$ in which interactions occur in homogeneous phase and, therefore, are not limited by mass transport [42-44]. Levofloxacin removals were highest in the $\mathrm{H}_{2} \mathrm{O}_{2} / \mathrm{UV}$ experiments, where values of $96.00 \pm 0.38,89.00 \pm 0.31$ and $82.00 \pm 0.27 \%$ were recorded at flow rates of 300,600 and $1200 \mathrm{~mL} \mathrm{~h}^{-1}$. Under these conditions, the decrease in removal of antibiotic with increasing flow rate is associated with the shorter retention time in the UV-irradiated area and the decreased formation of hydroxyl radicals.

Although the results presented in Fig. 3 show the apparent decline in antibiotic concentration, such reduction may not be associated necessarily with degradation because any change in the structure of levofloxacin could interfere with detection of the antibiotic under the chromatographic conditions employed. For this reason, the amount of TOC was determined in each of the experiments, from which the reductions in organic load could be evaluated.

In experiments carried out using acidic electrolyte containing $\mathrm{Fe}^{2+}$ ions but in the absence of $\mathrm{H}_{2} \mathrm{O}_{2}$ (GDE pressurized with $\mathrm{N}_{2}$ ), the removal of organic load was less than $25 \%$ at all flow rates studied (Fig. 4). The
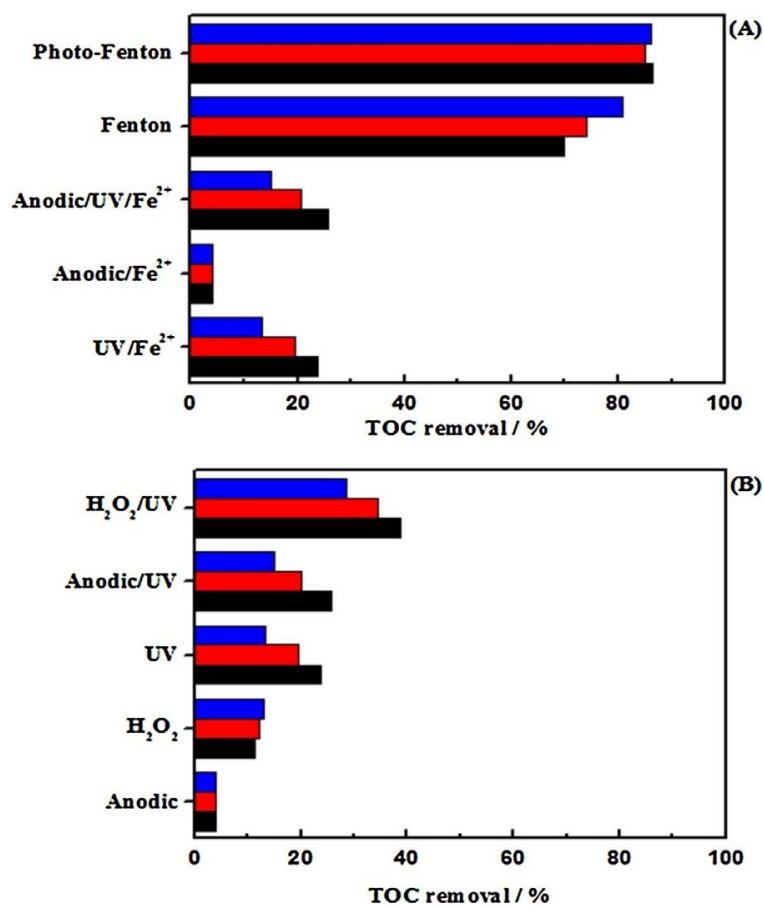

Fig. 4. Percentage removal of total organic carbon (TOC) in degradation experiments performed at $150 \mathrm{~mA} \mathrm{~cm}^{-2}$ and flow rates of $300(-), 600(-)$ and $1200(-) \mathrm{mL} \mathrm{h}^{-1}$ in: (a) acidic electrolyte containing $0.05 \mathrm{~mol} \mathrm{~L}^{-1} \mathrm{~K}_{2} \mathrm{SO}_{4}$ (adjusted to $\mathrm{pH}$ 2) plus $0.05 \mathrm{~mol} \mathrm{~L}^{-1} \mathrm{FeSO}_{4}$, and (b) alkaline electrolyte containing $0.05 \mathrm{~mol} \mathrm{~L}^{-1} \mathrm{~K}_{2} \mathrm{SO}_{4}$ and $0.1 \mathrm{~mol} \mathrm{~L}^{-1} \mathrm{KOH}(\mathrm{pH} 13)$. The initial solution used in all of the degradation experiments contains $130.1 \mathrm{mg} \mathrm{L}^{-1}$ of organic carbon. 
Table 1

Concentrations of nitrite and nitrate $\left(\mathrm{mg} \mathrm{L}^{-1}\right)$ in samples collected from degradation experiments performed at $150 \mathrm{~mA} \mathrm{~cm}^{-2}$ and $300 \mathrm{~mL} \mathrm{~h}^{-1}$ flow rate in the presence of acidic electrolyte containing $0.05 \mathrm{~mol} \mathrm{~L}^{-1} \mathrm{~K}_{2} \mathrm{SO}_{4}$ (adjusted to $\mathrm{pH}$ 2) plus $0.05 \mathrm{~mol} \mathrm{~L}^{-1}$ $\mathrm{FeSO}_{4}$, and alkaline electrolyte containing $0.05 \mathrm{~mol} \mathrm{~L}^{-1} \mathrm{~K}_{2} \mathrm{SO}_{4}$ and $0.1 \mathrm{~mol} \mathrm{~L}^{-1} \mathrm{KOH}(\mathrm{pH}$ 13).

\begin{tabular}{llllll}
\hline \multirow{2}{*}{ Anion } & \multicolumn{2}{l}{ Alkaline electrolyte } & & \multicolumn{2}{l}{ Acidic electrolyte } \\
\cline { 2 - 3 } \cline { 5 - 6 } & Anodic/UV & $\mathrm{H}_{2} \mathrm{O}_{2} / \mathrm{UV}$ & & Fenton & Photo-Fenton \\
\hline $\mathrm{NO}_{2}{ }^{-}$ & $0.40 \pm 0.01$ & $0.90 \pm 0.01$ & & $1.70 \pm 0.01$ & $1.90 \pm 0.01$ \\
$\mathrm{NO}_{3}{ }^{-}$ & $1.20 \pm 0.02$ & $1.50 \pm 0.01$ & & $3.80 \pm 0.01$ & $4.50 \pm 0.02$ \\
\hline
\end{tabular}

poor removal of organic carbon may be associated with mass transport limitation to the anode surface and/or on the incidence of UV irradiation [50]. Much higher values for TOC removal were recorded in experiments with $\mathrm{H}_{2} \mathrm{O}_{2}$ generation (GDE pressurized with $\mathrm{O}_{2}$ ), and maximum removal of $86.00 \pm 0.29 \%$ was attained under photo-Fenton conditions in which two separate processes were extant for the formation of hydroxyl radicals.

Interestingly, the electro-Fenton experiment exhibited a different behavior from other degradation experiments in that increasing the flow rate from 300 to $1200 \mathrm{~mL} \mathrm{~h}^{-1}$, promoted an increase in TOC removal from $70.00 \pm 0.25$ to $81.00 \pm 0.29 \%$. This behavior is associated with the greater generation of $\mathrm{H}_{2} \mathrm{O}_{2}$ at higher flow rates (as demonstrated in Fig. 2) which, in the presence $\mathrm{Fe}^{2+}$ ions, promotes an increase in TOC removal. Such behavior contrasts with that observed in the photo-Fenton experiment in which changes in flow rate did not influence TOC removal. It would appear that, under photo-Fenton conditions, the increase in $\mathrm{H}_{2} \mathrm{O}_{2}$ generation induced by a higher flow rate was offset by the decrease in retention time in the UV irradiation area, such that TOC removal remained at $86.00 \pm 0.37 \%$ at all flow rates studied.

With the aim of identifying the products formed during the degradation of levofloxacin, ion chromatography and HPLC-MS analyses were performed on samples collected in experiments that showed the best results for the removal of antibiotic and TOC, namely the electroand photo-Fenton experiments in acidic electrolyte and the anodic/UV and $\mathrm{H}_{2} \mathrm{O}_{2} / \mathrm{UV}$ degradations in alkaline electrolyte.

Table 1 shows the concentrations of nitrite and nitrate formed during degradation experiments conducted at $150 \mathrm{~mA} \mathrm{~cm}^{-2}$ and $300 \mathrm{~mL} \mathrm{~h}^{-1}$ flow rate in the presence of acidic and alkaline electrolytes. The concentrations of nitrate were higher in samples from experiments in which the degradation of organic load was greater, namely the electro- and photo-Fenton reactions in acidic medium. The lower concentrations of nitrite in comparison with nitrate can be associated with different bond rupture in the levofloxacin molecule, as described by Rezende et al. [50], together with the partial oxidation of nitrite to nitrate that occurs in the presence of excess hydroxyl radicals in acidic medium.

Samples of electrolyte collected during the electro- and photoFenton degradations of levofloxacin in acidic medium were submitted to HPLC-MS analysis, and the by-products formed during the processes were identified from the respective mass spectra.

All of the proposed intermediates on the route of degradation of levofloxacin outlined in Fig. 5 were detected by HPLC-MS with the exception of VI, the inclusion of which was based on theoretical considerations. It is likely that the failure to detect these two intermediates was associated with the instability of the structures during the degradation process. The initial step in the proposed degradation route involves the elimination of a $-\mathrm{NCH}_{2} \mathrm{CH}_{2} \mathrm{NCH}_{2} \mathrm{CH}_{2} \mathrm{CH}_{3}$ group from the levofloxacin molecule (I; $m / z=361)$ to form fragments II $(m / z=282$ ) and III $(m / z=91)$. It is important to note that, at this early stage, the detected fragments correspond to those produced through molecular

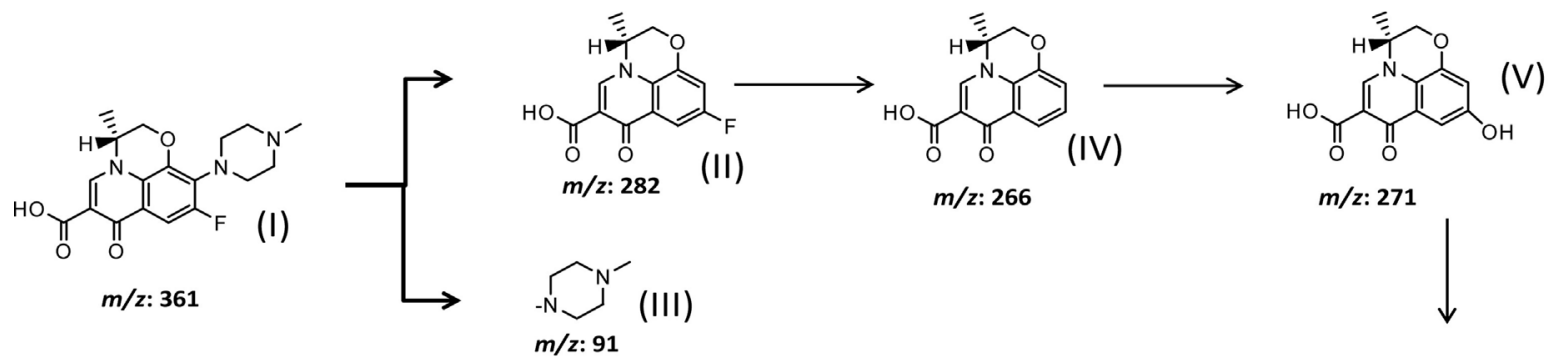

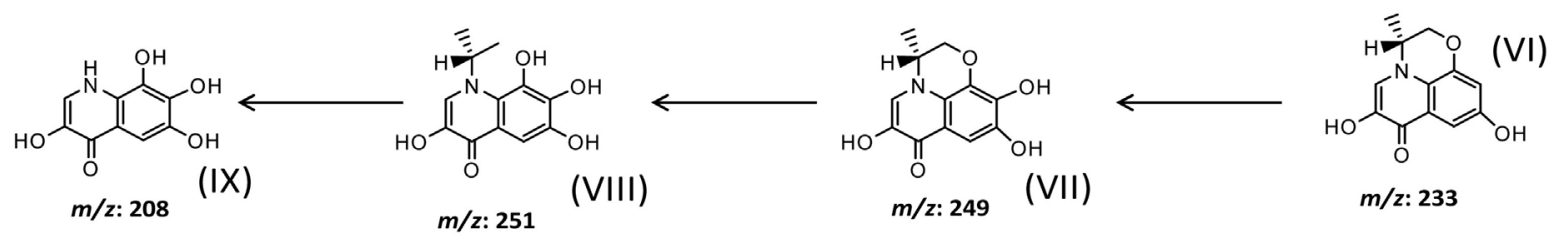

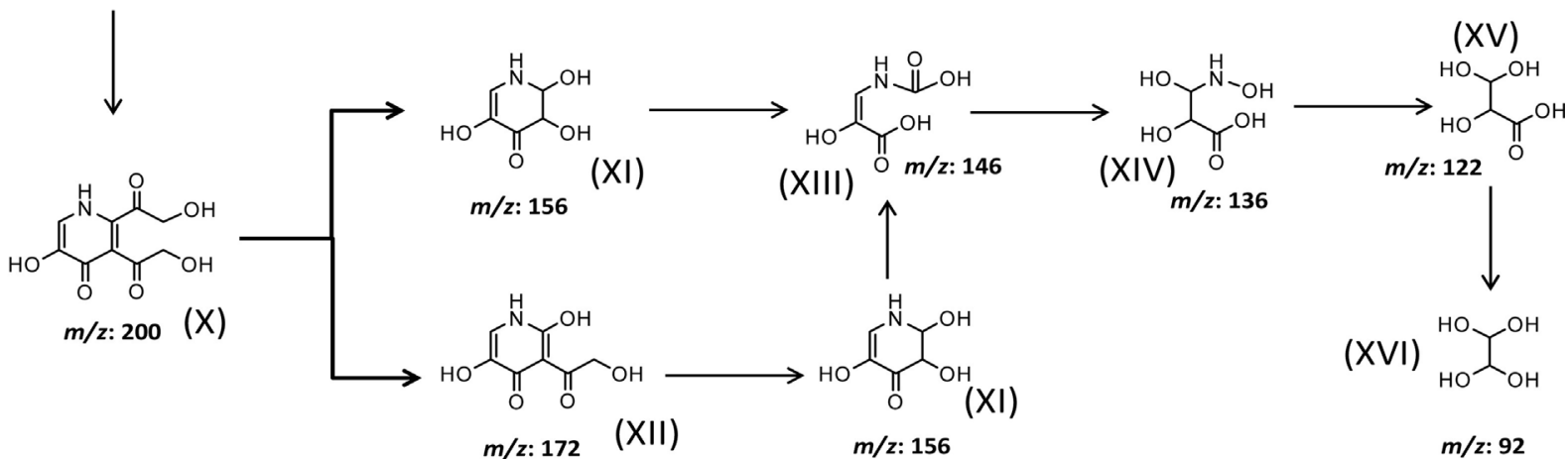

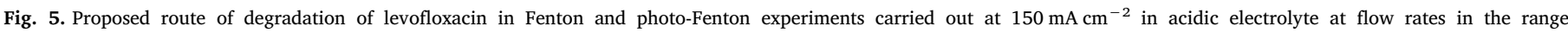
300-1200 $\mathrm{mL} \mathrm{h}^{-1}$. 
cleavage brought about by MS and are not specific products of oxidation.

In the following step, the fluoride group of II is substituted by hydride, to yield fragment IV $(m / z=266)$, and subsequently abstracted with insertion of a hydroxyl group to generate the oxidation product $\mathrm{V}$ $(m / z=271)$. In reaction medium containing excess hydroxyl radical, the carboxyl grouping of $\mathrm{V}$ may undergo decarboxylation followed by insertion of a hydroxyl group to form the hypothetical oxidation product VI $(m / z=233)$. In a saturated environment, insertion of a hydroxyl group into the aromatic ring of VI may occur to yield the identified product VII $(m / z=249)$. Rupture of the cyclic ligand in this highly substituted and tensioned molecule would generate the fragment VIII $(m / z=251)$, which subsequently loses an $-\mathrm{CHCH}_{3} \mathrm{CH}_{3}$ group forming fragment IX $(m / z=208)$. In the subsequent step, the aromatic ring is ruptured, producing fragment $X(m / z=200)$, and successive hydride abstractions and hydroxyl insertions occur at the double bonds to generate oxidation products XI $(m / z=156)$ and XII $(m / z=172)$. In the final steps, opening of the hetero ring would yield products XIII ( $\mathrm{m} /$ $z=146)$ and XIV $(m / z=136)$ with formation of the aliphatic acid XV $(m / z=122)$, which is one of the major intermediates prior to the formation of oxalic acid (XVI; $m / z=92$ ) and, ultimately, $\mathrm{CO}_{2}$ and $\mathrm{H}_{2} \mathrm{O}$.

\section{Conclusion}

The generation of $\mathrm{H}_{2} \mathrm{O}_{2}$ was evaluated using an electrochemical reactor operated in the single pass flow mode in which the electrolyte passed over the electrodes only once and was sampled at the system exit. In this mode of operation, $\mathrm{H}_{2} \mathrm{O}_{2}$ generation by electrochemical oxygen reduction was related directly to the flow rate of electrolyte and reached a maximum of $10.8 \mathrm{mg} \mathrm{L}^{-1} \mathrm{~cm}^{-2}$ and $10.3 \mathrm{mg} \mathrm{L}^{-1} \mathrm{~cm}^{-2}$ in alkaline and acidic medium, respectively, at the highest flow studied $\left(1200 \mathrm{~mL} \mathrm{~h}^{-1}\right)$. High levels of removal of levofloxacin were attained when the electrochemical reactor was coupled with a UV lamp, giving a reduction in concentration of the antibiotic of around 99\% when degradations were performed in acidic electrolyte containing $\mathrm{Fe}^{2+}$ ions. Under these conditions, the electrochemical/UV system showed $\sim 86 \%$ removal of organic load with the concomitant formation of $4.5 \mathrm{mg} \mathrm{L}^{-1}$ of nitrate and $1.9 \mathrm{mg} \mathrm{L}^{-1}$ of nitrite. HPLC-MS analysis of the samples of electrolyte from the electro- and photo-Fenton experiments allowed the majority of by-products of levofloxacin degradation to be identified up to and including the aliphatic compounds formed in the last oxidation step prior to complete mineralization.

\section{Acknowledgements}

This work was supported by São Paulo Research Foundation [FAPESP; grant \#2013/02762-5, \#2014/50945-4, \#2013/16690-6, \#2014/11486-4, \#2016/01937-4]; Coordenação de Aperfeiçoamento de Pessoal de Nível Superior [CAPES]; and Conselho Nacional de Desenvolvimento Científico e Tecnológico [CNPq; grant numbers 301492/2013-1; 446436/2014-3，301492/2013-1; 465571/2014-0 (INCT-DATREM)].

\section{References}

[1] N.H. El Najjar, A. Touffet, M. Deborde, R. Journel, N.K.V. Leitner, Chemosphere 93 (2013) 604-611.

[2] Y. Li, D. Wei, Y. Du, Chemosphere 119 (2015) 282-288.

[3] M. Sturini, A. Speltini, F. Maraschi, A. Profumo, L. Pretali, E.A. Irastorza, E. Fasani, A. Albini, Appl. Catal. B Environ. 119-120 (2012) 32-39.

[4] H. Wei, D. Hu, J. Su, K. Li, Chin. J. Chem. Eng. 23 (2015) 296-302.

[5] T. An, H. Yang, W. Song, G. Li, H. Luo, W.J. Cooper, J. Phys. Chem. A 114 (2010) 2569-2575.

[6] W. Guo, Y. Shi, H. Wang, H. Yang, G. Zhang, Ultrason. Sonochem. 17 (2010) 680-684.
[7] X. Hu, J. Fan, K. Zhang, N. Yu, J. Wang, Ind. Eng. Chem. Res. 53 (2014) 14623-14632.

[8] B. Puértolas, A.K. Hill, T. García, B. Solsona, L. Torrente-Murciano, Catal. Today 248 (2015) 115-127.

[9] R.D.C. Soltani, A. Rezaee, A.R. Khataee, H. Godini, Res. Chem. Intermed. 39 (2013) 4277-4286.

[10] B.D. Witte, H.V. Langenhove, K. Hemelsoet, K. Demeestere, P.D. Wispelaere, V.V. Speybroeck, J. Dewulf, Chemosphere 76 (2009) 683-689.

[11] I. Ahmad, R. Bano, M.A. Sheraz, S. Ahmed, T. Mirza, S.A. Ansari, Acta Pharm. 63 (2013) 223-229.

[12] M.H.M.T. Assumpção, R.F.B. de Souza, R.M. Reis, R.S. Rocha, J.R. Steter, P. Hammer, I. Gaubeur, M.L. Calegaro, M.R.V. Lanza, M.C. Santos, Appl. Catal. B Environ. 142-143 (2013) 479-486.

[13] W.R.P. Barros, S.A. Alves, P.C. Franco, J.R. Steter, R.S. Rocha, M.R.V. Lanza, J. Electrochem. Soc. 161 (2014) H438-H442.

[14] G.S. Cordeiro, R.S. Rocha, R.B. Valim, F.L. Migliorini, M.R. Baldan, M.R.V. Lanza, N.G. Ferreira, Diamond Relat. Mater. 32 (2013) 54-60.

[15] H.S. El-Desoky, M.M. Ghoneim, R. El-Sheikh, N.M. Zidan, J. Hazard. Mater 175 (2010) 858-865.

[16] M.J. Gómez, M.J. Martínez Bueno, S. Lacorte, A.R. Fernández-Alba, A. Agüera, Chemosphere 66 (2007) 993-1002.

[17] M.J. Gómez, C. Sirtori, M. Mezcua, A.R. Fernández-Alba, A. Agüera, Water Res. 42 (2008) 2698-2706.

[18] Y. Hou, J. Qu, X. Zhao, H. Liu, J. Environ. Sci. 21 (2009) 1321-1328.

[19] S.K. Kansal, P. Kundu, S. Sood, R. Lamba, A. Umar, S.K. Mehta, New J. Chem. 38 (2014) 3220-3226.

[20] M.W. Lam, S. Mabury, Aquat. Sci. 67 (2005) 177-188.

[21] A. Özcan, Y. Sahin, A.S. Koparal, M.A. Oturan, J. Electroanal. Chem. 616 (2008) 71-78.

[22] J.R. Steter, R.S. Rocha, D. Dionísio, M.R.V. Lanza, A.J. Motheo, Electrochim. Acta 117 (2014) 127-133.

[23] M. Sturini, A. Speltini, F. Maraschi, L. Pretali, A. Profumo, E. Fasani, A. Albini, R. Migliavacca, E. Nucleo, Water Res. 46 (2012) 5575-5582.

[24] M. Sturini, A. Speltini, F. Maraschi, L. Pretali, A. Profumo, E. Fasani, A. Albini, Environ. Sci. Pollut. Res. 21 (2014) 13215-13221.

[25] A. Tauxe-Wuersch, L.F. de Alencastro, D. Grandjean, J. Tarradellas, Water Res. 39 (2005) 1761-1772.

[26] M.H.M.T. Assumpção, A. Moraes, R.F.B. de Souza, M.L. Calegaro, M.R.V. Lanza, E.R. Leite, M.A.L. Cordeiro, P. Hammer, M.C. Santos, Electrochim. Acta 111 (2013) 339-343.

[27] J.-Y. Chen, N. Li, L. Zhao, J. Power Sources 254 (2014) 316-322.

[28] R.M. Félix-Navarro, M. Beltrán-Gastélum, M.I. Salazar-Gastélum, C. Silva-Carrillo, E.A. Reynoso-Soto, S. Pérez-Sicairos, S.W. Lin, F. Paraguay-Delgado, G. AlonsoNúñez, J. Nanopart. Res. 15 (2013) 1802.

[29] G.P. Perez, J.M. Bisang, J. Chem. Technol. Biotechnol. 89 (2014) 528-535.

[30] E.P. Randviir, C.E. Banks, Electroanalysis 26 (2014) 76-83.

[31] G. Xia, Y. Lu, H. Xu, Electrochim. Acta 158 (2015) 390-396.

[32] X. Yu, M. Zhou, G. Ren, L. Ma, Chem. Eng. J. 263 (2015) 92-100.

[33] F. Yu, M. Zhou, X. Yu, Electrochim. Acta 163 (2015) 182-189.

[34] R.M. Reis, A.G.F. Beati, R.S. Rocha, M.H.M.T. Assumpção, M.C. Santos, R. Bertazzoli, M.R.V. Lanza, Ind. Eng. Chem. Res. 51 (2012) 649-654.

[35] Y. Gendel, H. Roth, A. Rommerskiechen, O. David, M. Wessling, Electrochem. Commun. 46 (2014) 44-47.

[36] G.A. Kolyagin, V.L. Kornienko, Russ. J. Appl. Chem. 84 (2011) 68-71.

[37] G.A. Kolyagin, V.L. Kornienko, Russ. J. Electrochem. 50 (2014) 798-803.

[38] G.A. Kolyagin, I.S. Vasil'eva, V.L. Kornienko, Russ. J. Electrochem. 47 (2011) $282-287$.

[39] G.A. Kolyagin, V.L. Kornienko, Y.A. Kudenko, A.A. Tikhomirov, S.V. Trifonov, Russ. J. Electrochem. 49 (2013) 1004-1007.

[40] V.L. Kornienko, G.A. Kolyagin, G.V. Kornienko, N.V. Chaenko, A.M. Kosheleva, T.A. Kenova, I.S. Vasil'eva, Russ. J. Appl. Chem. 87 (2014) 1-15.

[41] O. Modin, K. Fukushi, Sci. Water Technol. 66 (2012) 831-836.

[42] H. Wang, D.-Z. Sun, Z.-Y. Bian, Degradation mechanism of diethyl phthalate with electrogenerated hydroxyl radical on a Pd/C gas-diffusion electrode, J. Hazard. Mater. 180 (2010) 710-715.

[43] H. Wang, Z.Y. Bian, D.Z. Sun, Sci. Water Technol. 63 (2011) 484-490.

[44] H. Wang, Z. Bian, G. Lu, L. Pang, Z. Zeng, D. Sun, Appl. Catal. B Environ. 125 (2012) 449-456.

[45] I. Yamanaka, T. Onisawa, T. Hashimoto, T. Murayama, ChemSusChem 4 (2011) 494-501.

[46] H. Wang, J. Wang, Appl. Catal. B Environ. 77 (2007) 58-65.

[47] W.R.P. Barros, M.P. Borges, R.M. Reis, R.S. Rocha, R. Bertazzoli, M.R.V. Lanza, J. Braz. Chem. Soc. 25 (2014) 1673-1680.

[48] M.H.M.T. Assumpção, A. Moraes, R.F.B. de Souza, I. Gaubeur, R.T.S. Oliveira, V.S. Antonin, G.R.P. Malpass, R.S. Rocha, M.L. Calegaro, M.R.V. Lanza, M.C. Santos, Appl. Catal. A Gen. 1-6 (2012) 411-412.

[49] R.S. Rocha, Beati André A.G.F, J.G. Oliveira, M.R.V. Lanza, Avaliação da degradação do diclofenaco sódico utilizando $\mathrm{H}_{2} \mathrm{O}_{2}$ /Fenton em reator eletroquímico (Evaluation of the degradation of sodium diclofenac using $\mathrm{H}_{2} \mathrm{O}_{2}$ /Fenton in an electrochemical reactor), Quim. Nova 32 (2009) 354-358.

[50] L.G.P. Rezende, V.M.D. Prado, R.S. Rocha, Beati André A.G.F, M.D.P.T. Sotomayor, M.R.V. Lanza, Quim. Nova 33 (2010) 1088-1092. 